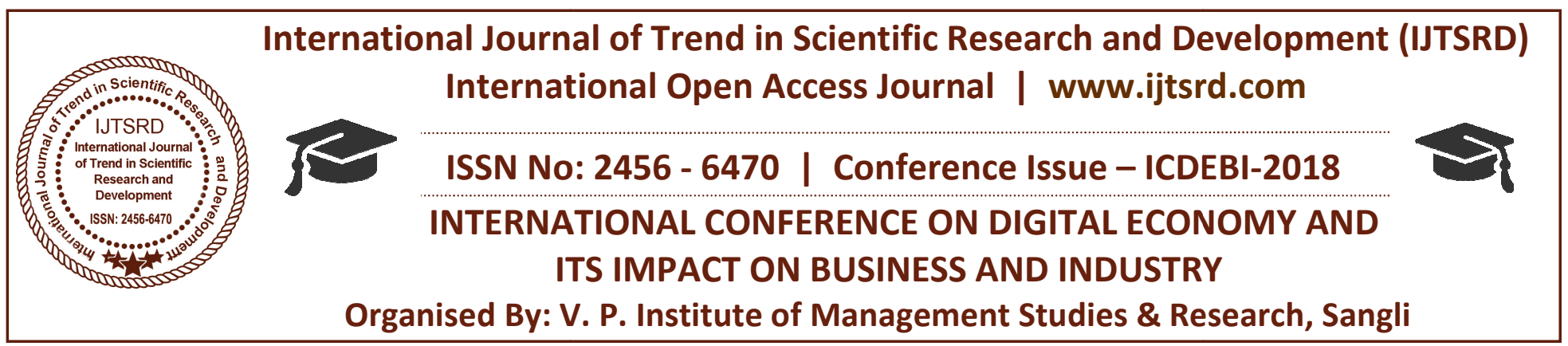

\title{
Success of Digitalisation in Tourism Industry in India
}

\author{
Swati Ajay Shigaonker \\ Assistant Professor, MES College of Arts \& Commerce, Zuarinagar, Goa, India
}

\section{ABSTRACT}

Digitization offers many new opportunities that can be exploited by providers in the tourism industry. At the same time, competition is being intensified and companies have to keep pace with digitization in order to remain on the same level. Without any question, "digitization can be viewed as the motor of transformation for the tourism industry in the age of the internet economy

Today, more than $57 \%$ of all travel reservations each year are carried out with the internet and internet travel booking revenue has grown by more than $73 \%$ over the past 5 years, while $65 \%$ of tourist book hotels reservations for the same day are made on a mobile device. In the course of this development, travel providers need to tackle the challenges of individually addressing different stakeholders from country to region through knowledge, time, and a sophisticated strategy. Professional digitization strategies of travel providers such as classic travel agencies require resources such as specialists with IT expertise and a certain budget. In return, the introduction and implementation of a digitization project in the tourism sector might lead to considerable cost savings and productivity gains. Significant examples of this are the automation of work-flows, the increase in employee motivation as well as cost and time savings.

This paper is theoretical in nature and based on secondary data. An attempt is made through this research paper to understand the success rate or degree of digitalization that has taken place, so far, in travel and tourism industry which is one of the chief source of employment of any country in the world. Being a comparatively non polluting industry, digitalization will rake in huge amount of revenue for cash starved country like India.
KEYWORD: Digitization, opportunities, travel reservations, mobile device, cost savings, productivity.

\section{INTRODUCTION}

India's traditional outlook received a jolt when the decree of demonetization dawned on them as India, under the leadership of Narendra Modi, envisaged a cashless economy. Spirited responses from the citizens of the country despite initial hiccups have also encouraged further measures. The travel and tourism sector, along with the traditional hotel industry, was one of the prime sectors that witnessed a drastic slowdown during the last couple of months of 2016.

Transformation in travel and tourism industry has certainly led to rise in numbers of people travelling across the globe. According to UNWTO from 674 million in 2000, the overall international tourist arrivals have grown to 1,186 million in 2015 . International tourist arrivals worldwide are expected to increase by $3.3 \%$ a year between 2010 and 2030 to reach 1.8 billion by 2030. These figures are evidence about the potential travel and tourism industry carries and how digital transformation in this landscape will benefit.

According to a recent report by Ministry of Tourism, the travel and tourism contributed nearly US\$295.7 billion or 19.2 per cent to the GDP in 2015-16, while growing at 8.9 per cent year-on-year. Also, the industry is expected to generate 13.45 million jobs across sub-segments such as hotels, travel agents/tour operators and restaurants.

Today one doesn't need to visit a travel agent or tour operator to get hold of various destinations and their 
offerings. Internet or rather the advent of technology has educated a consumer in such a depth that they are now the new experts. The need of a travel agent to some extent is getting limited to handling the backend processes of operating a tour or holiday for their customers, which is still not better handled by technology. The last decade has witnessed massive changes credit to rise in usage of technology. The shift created by technology can be seen across all verticals irrespective of the industry. From aviation to hospitality to B2B travel trade, technology has emerged as the game changer. The very fact that the consumer has easy and detailed access to technology led to the change in the landscape of travel industry across the globe.

With the development of technology over the last decade now there is no or slight difference between a tourist and a traveller. A traveller can anytime become a tourist with the help of knowledge he gains from the internet about the destination he is travelling to. Technology has changed the way people plan, research and book their travel arrangements. Talk about mobile ticketing, online check-ins at airports and hotels, e-visas, digital payments, elaborated information's about the destinations one is travelling to or be it about the Google maps and other related stuffs, cutting out the fear of getting lost in an unknown country, the small digital device in one's hand is enough to handle all the basic travel needs.

\section{OBJECTIVES OF THE STUDY}

The paper explores how digitalisation will help better define the future of the industry and how the new trend will impact the evolution of the travel, tourism and hospitality sector in the country. The paper also takes a keen look at how the overall technology inclusion among the stakeholders in the industry ecosystem can be realized.

1. To understand the concept of digitalization in travel \& tourism

2. To understand the contribution of mobiles, social media, online travel booking in the growth and success of tourism industry

3. to understand the challenges faced by the travel and tourism industry in India

4. to evaluate the future prospects.

\section{DATA COLLECTION}

Data is collected from secondary sources. The research paper is descriptive in nature and analyses the contribution of various technologies like mobiles, social media, and internet in the success of travel and tourism industry in India.

\section{MOBILE TECHNOLOGIES}

Today, the mobile phone signal is pervasive, and the use of cell phones and internet services is booming. In fact, the world's poorest households are less likely to have access to a toilet than to a mobile phone. While this unfortunately holds true for India, it also highlights the country's digital transformation. Today, India has over 1 billion mobile subscriptions, more than 400 million internet users and a social media penetration of $14 \%$. While India's progress is significant, untapped potential remains.

The entire Indian travel and tourism ecosystem has evolved as a result of mobile technologies. Digital players, such as MakeMyTrip, Ola and OYO Rooms, have helped connect the market digitally, and even enabled the country to leverage alternative accommodation.

Consumers search for information before a trip, they compare and check opinions of other travelers, and then they reserve tickets, hotels, and even tickets for shows and museums. During the trip, from online check-in to looking up information about restaurants and leisure activities. After traveling, they add their review to the information that other travelers will consult. All of this is done on a mobile device in more After travelling, they add their review to the information that other travellers will consult. All of this is done on a mobile device in more than $50 \%$ of cases.

\subsection{Increasing prevalence of mobile technologies}

$>$ Smartphone's generated one in five online hotel bookings in the second quarter of 2016.

$88 \%$ of travellers with smart phones would switch to another site or app if yours doesn't satisfy their needs

Research by Google shows that an increasing amount of time is spent researching trips on mobile phones, with $40 \%$ of US travel site visits coming from mobile in 2016. Visit session times are shrinking and yet conversion rates have grown by nearly $10 \%$ on mobile travel sites. Customers are using their phones to search for specific pieces of information and these figures suggest that if they don't find it they will quickly go elsewhere. 


\section{THE NEW SHAPE OF SOCIAL MEDIA}

Digital Innovation Technology has certainly led to innovations. Travel and tourism is now becoming personalised day by day. Each person has his own travelling style and own needs. With the help of technology, a traveller is now able to reach out the perfect choice. Trip Advisor, Zomato, etc., help a traveller choose his ideal preferences. Trip Advisor now claims over 300 million unique monthly visitors to its websites, and carries over 200 million independent reviews. Social media platforms have helped decide where they want to travel. Brochures and presentations about destinations are old school and digital platforms are being used for marketing a destination. Geo-tagging on Instagram and Facebook have helped a lot of destinations and properties to gain popularity. Bigger brands are concentrating their efforts on digital marketing to be in the race. To give an example, St. Regis Mumbai, launched in 2016, has certainly grown out to be one of the top brand hotels in Mumbai and the management gives credits to social media for their success. Vinay Singh, Director of Sales \& Marketing, St. Regis Mumbai, exclaimed, "In the era of digitalisation, one would be out of league if absent on social media. St. Regis Mumbai is certainly not behind on social media marketing front. We are ranked number two in terms of Geo-tagging and in terms of Instagram followers. We are analysing what is the need of the hour and are innovating our services to meet the new demands. Trip Advisor is one of the biggest platforms today to look out for best hotels in a city and our next target is to be among the top five hotels in the business capital of India in Trip Advisor's ratings."

\section{PARAIDIGM SHIFT}

There has been a paradigm shift in the travel industry around the world. Traditional travel agents have been forced to modify and innovate their working style due to birth of online travels agents (OTAs) and direct distribution of services by airlines and hotels' websites. How OTAs have marketed themselves through digital mediums and have eventually helped consumers with the ease of travelling across the globe is a thing to be learned. Travel agents are now certainly working towards digital expansions which will help them reach out the consumer especially millennial, Gen X consumer which refuses go a step ahead without technology. Innovating and offerings their services in a tech-friendly manner and through digital mediums is the key to success for traditional travel agents in today's ever changing landscape.

\subsection{Success through Technology}

The correct and optimum use of technology has led to the success of OTAs to a greater extent. They have targeted the Genx style of travelling. Travelling to a destination still needs an aircraft, to stay one still needs a hotel and to eat one still needs a restaurant. This was offered previously too but the present day condition is OTAs have worked towards easing out and accelerating these processes. Now one is not afraid to stay at a stranger's home because of Airbnb and similar home stay options. Reviews and ratings have helped tourists make a choice of cuisines. Ecommerce platforms like online payment, traveller cards, etc., have reduced the tension of people carrying cash and doing foreign exchange, etc. Neelu Singh said, "Over the years, technology has helped create wider content, increased efficiency in travel transactions and faster tools that help agents to sell destinations and up sell additional services that the customer might choose to buy without increasing any complication of the booking process. Innovations in technology have created a seamless, convenient and connected experience for travellers and travel providers. Innovations in data convergence, reputation management, mobile commerce, digital transformation and automation has helped shape the travel ecosystem in a way that it enabled travel companies to offer not just products but also services that match customer expectations."

\subsection{Digital technology and changing consumer behavior}

The progression of digital technology continues to raise expectations and alter customer behaviors. Consumers are becoming increasingly empowered and discerning with the wealth of information available online. Trust and ease of fulfillment is now a key to decision-making and personalization form an integral part of this process. In a market where there is endless choice, and where customers are wary of being misled, established brands can succeed by easing the path to purchase. User experience (or UX) has become the top priority for both customer retention and advocacy.

\section{NEXUS BETWEEN DIGITALIZATION AND CUSTOMER USE}

\section{Searching for information before the trip:}

Perhaps the most widespread use, since today more than $90 \%$ of users check information on the Internet before reserving a trip or hotel. This translates into a responsive website and even into 
versions directly envisioned for mobile devices, apps, and useful, quality content creation for the user,

\section{Checking recommendations:}

Although this is part of the process of searching for information before the trip, in many cases, it is done via other channels, not on the company's website, therefore following up with and responding to reviews, especially negative ones.

\section{$>$ Online check-in and check-out:}

among the most pragmatic functions, especially for reserving hotels and flights, the possibility to check in online saves time and paperwork for the customer and improves the company's internal management.

\section{Secure reservation and purchase process:}

Increases in online reservations and purchases have also brought with it increased user concern for the security of their personal and financial data. One of the main challenges for any company is to implement disruptive solutions that offer high security in data handling while not causing a poor user experience, since this leads to high percentages of abandonment in the reservation and purchase process.

\section{$>$ App development:}

users also search for information during the trip, which has fostered development of both general and specialized apps. In the case of hotels, they can serve to provide information about places and activities both in and outside of the hotel, with mobile services customized according to user preferences. Apps can be developed by tourism organizations and governments themselves to promote local tourism.

\section{Smart cities:}

Some towns, taking a step further in developing apps, have begun to implement geolocating smart systems with beacons that provide useful information for tourism: weather, hotels, culture, Transportation and even additional services such as supervision systems for children.

\section{$>$ Connectivity:}

Free mobile connectivity is essential now for many users, both $\mathrm{Wi}-\mathrm{Fi}$ and $4 \mathrm{G}$, for example. Internet connections are not only offered now in most hotels and other establishments such as restaurants and airports, but there are also areas implementing free $\mathrm{Wi}-\mathrm{Fi}$ throughout the whole city.

\section{Access to devices:}

Some chains offer their client's devices such as tablets or smart phones during their hotel stay as a courtesy or for a small rental fee, offering access to tourist information and entertainment and practical information. Directly on their website.

\section{New business models:}

The high availability of users and the ability to geolocate them allow for additional, much more customized services, even new services such as reservations at the destination. This trend is even higher both among young people who travel without a set plan and reserve a hotel when they are already at their destination, and in business trips, which are often subject to last-minute changes.

\section{Sector-based focus:}

Apps focused on specific sectors are yielding excellent results in the entertainment and tourism sector, since they meet very concrete needs, such as the third sector, family tourism with children, the elderly, singles, the LGBT community, and even interest-based travel such as ornithology, hiking, scuba diving, or literary tours.

\section{Augmented and virtual reality:}

Beyond mobile devices, augmented and virtual reality experiences can be offered, such as the digital observatory of the Barcelona Skyline at Terraza 83,3, which provides information about the monuments thanks to augmented reality technology, and which also allows immersive visits to some of the monuments with virtual reality goggles.

\section{ONLINE TRAVEL INDUSTRY - INDIAN SCENARIO}

D The mobile apps have changed the way in which customers interact with brands and vice versa. With Smartphone adoption growing at a phenomenal rate, the number of travel-related searches and bookings via mobiles has skyrocketed in the past year. 
The Indian government is now taking more initiatives to make various travel and tourism affairs go digital. The fresh approaches are to change the way both international and domestic tourists travel.

Various travel arrangements, like booking of entrance tickets, have been transformed. A traveler can reserve tickets even before they set foot in India. E-tickets can now be booked for visiting 116 monuments across the country. The services have also been extended to mobile phones, letting travelers enjoy and benefit from the new e-platforms. While in a monument, tourists can use their phones to access the available audio-visual guides and combine them with venue-specific barcodes encapsulating complete information.

"The 1363 helpline in 12 languages is a unique effort. It is available nowhere in the world. You may find the local language and English but here we have a mix of languages spoken by tourists. So there is an ease of experience. We have made eticketing for 116 monuments where you do not need to stand in a queue. Now you can start from your hotel or even your country with the e-ticket for that particular monument. There is a barcode chart accessible on your mobile that has complete information on a site or organization," says an official of the tourism ministry.

$>$ The helpline also offers human's assistance that can be availed by dialing a "tourist's friend" or a tourist facilitator."We are inducting ex-army-men for the purpose and we hope this will help us ensure a sense of safety," the official adds.

The various languages have also been updated on Incredible India's new website, which will be launched soon. To help the foreign visitors, it will have a lot of details including various travelrelated services, prices, comparators, and certified experiential.

\section{TOURIST E- VISA FACILITY}

The government's 'e-Tourist Visa' facility continued to witness an increase in applications, with nearly 1.08 million tourists arriving through it in 2016 - a significant 142.5 per cent growth. There are continuous speculations about the feasibility of the plan and its ground-level hitches since the electronic visa on arrival scheme surfaced in November 2014. Ambiguities prevailed regarding issues such as payment gateway issues, unresponsive websites and the confusion regarding the availability of e-visa more than twice in a calendar year. Moreover, complaints about the inconsistency of the application form and its low-responsive nature have also diluted the intention of encouraging foreign tourist arrival.

The tourism ministry probably wanted to encourage foreign individuals to travel with a short-term planning, take via routes while travelling to other countries and bring family members while on business visits to India. However, the overall numbers although shown in glorious percentages are far from being satisfactory. While experts believe that India is failing to gain grounds due to lack of proper representation in the international markets, the inconsistent tourism policies can be held responsible for the meagre growth over the last two years.

\section{CHALLENGES FACED BY INDIAN TRAVEL AND TOURISM INDUSTRY.}

1. Inadequate broadband infrastructure and related service quality

Impact the effective and timely completion of electronic payment transactions, which are critical for the travel and tourism industry. In fact, there is a direct correlation between information communications technology (ICT) readiness and tourism receipts. The travel and tourism industry, like the majority of service industries, is witnessing a rise in services provided through mobile devices, with an increase from $9 \%$ in 2015 to $33 \%$ in 2016 . The increase in mobile device penetration has enabled geotagging and the customization of services as a result of an improved understanding of individual preferences and behaviours. Through digitalization, India will be better able to deliver experiences to travellers and promote its destination.

\section{For the traditional travel agents going digital is the path to followed.}

They have to get smart and adapt to the changing environment. In the coming years, things will become more complicated for traditional agents as the change is inevitable. Delivering a personalised experience through the help of digital mediums can be the only possible way to stand among the elites of present day travel and tourism industry. 
3. Consumer expectations are changing.

Making a task easier is the top motivating factor for downloading travel apps, Ease of use and navigation is nearly twice as important as any other travel app feature. When people have a negative brand experience on mobile, they are $62 \%$ less likely to purchase from that brand in the future than if they have a positive experience. $59 \%$ of people are likely to recommend a brand if it delivers a frictionless experience across channels

\section{Cash constraints and the culture.}

There is a big pressure on costs as well as acquiring new guests. With the pressure on the business and the margins, travel companies will have to keep working on cost reduction. And the cost reduction can happen only by increasing the productivity of the employees. A lot of work is to be done on process reengineering, automation and tools for performance improvement.

\section{SUCCESS OF DIGITALISATION IN INDIA -} THE FUTURE

1. There is nothing constant in this world and this applies to technology as well. Technology interface keeps on innovating itself thereby challenging its users to adapt to every change. OTAs that are already performing well also have to cope-up with this change. Solution they have opted is either merger and acquisitions or innovating their services.

2. Recently Ola Cabs partnered with Google maps to provide Ola Outstation Cabs on Google maps. Similarly MakeMyTrip now has a 24 by 7 customer care centre assisting its customers with ease of operations and stays. Companies are studying the reviews of people on social media and analysing them to offer better customer experiences. Customer involvement has now been extended with the rise in usage of technology.

3. Many tourism and hotel companies are not just putting their web or offline functions in mobile format, but they are also creating experiences and new business models designed specifically for the mobile channel.

4. We could say that mobile technology is developing so quickly that it is hard to get an idea of all the potential it holds for the tourism and travel sector. The digital transformation clearly happens when you listen to clients, understand them, and constantly offer them unique experiences.

5. The travel and tourism industry therefore has also been at the forefront of driving the digital development. $\mathrm{Be}$ it in the form of digital marketing techniques, digitization of paper tickets, digitization in payments or hitherto offline post sales services. The long-term players in the industry will constantly have to be on their toes to design unique ways to offer varied services to their target audience.

6. Data science is an area, where a decade or more of history with customers should lead to better suggestions and customization. Another key enabler that has given boost to the online travel industry is the 'Big Data', as it enables the travel companies to engage better with customers and deliver service efficiently and intelligently. It provides us a great opportunity to positively impact both the business-end and the experience at the customer-end through better decisionmaking, greater product and service innovation and stronger customer relationships that will be delivered by new approaches to customer management, revenue management and internal operations. Indian online travel booking space is in the midst of a critical churning.

7. Mobile has become the most secular driver of online travel business. It has helped in geo tagging and providing relevant content to customers who for the longest time have been used to offline buying of travel services in destination. This has also led to significant growth in last minute bookings on the mobile. The mobile platform is only getting better and bigger. From e-commerce, we are heading to $\mathrm{m}$-commerce era at a fast pace thanks to mobile which is now an indispensable companion available on a $24 \times 7$ basis. More importantly, the bandwidth has significantly improved. The entire eco-system which we are noticing today has fundamentally evolved because of mobile. There are three possible disruptors in the space: The mobile internet/app revolution is one of the biggest growth drivers for the industry at large. It has connected many more people in India and expanded the addressable market for companies like ours. 
8. The emergence of mobile wallets such as Paytm, PayU and others supplemented this trend by making the payments side of things more democratic. Gone are the days when debit cards were not used for online transactions. Having said that, much more needs to be on the payments side.

9. The accommodation market in India has opened up to beyond branded hotels thanks to digital tools being leveraged to aggregate unbranded hotels or alternative accommodations.

10. The government's e-tourist visa programmed continues to gain traction, with a sharp rise in applications in October 2016. Digital Solutions enhancements are the need of the hour as it really does help the flow of travel.

11. Most OTAs offer packages with custom destination, itinerary, flight and hotel bookings and discounts. Portfolio can be enhanced with things like fare alerts service for flights, progressive web app for hotels, Trip Assistant, hotel check in experience or assist, Personalized hotel search, easy location search for hotels , instant refunds on domestic flights \& hotels.

\section{CONCLUSION}

The Indian travel and tourism sector also contributes significantly to the country's GDP and employment. The direct contribution of travel and tourism sector which reflects the net value of output generated by hotels, airlines, travel agents, other passenger transportation services (excluding commuter services), and restaurants and leisure industries directly supported by tourists - was expected to rise 6.9 per cent $\mathrm{y}-\mathrm{o}-\mathrm{y}$ in 2017. This account for 3.3 per cent of the country's GDP, and is expected to form 3.5 per cent of it by 2027. In accordance with its GDP contribution, the sector contributes significantly to job creation. The sector directly accounts for 5.8 per cent of the total employment in India. Further, the Indian travel and tourism sector is expected to have attracted capital investment of INR2, 387.7 billion (USD35.2 billion) 03, 04 in 2017 - accounting for 5.7 per cent of the total national investment.

The rapid digitization offers a rare opportunity to disrupt rather than go for incremental changes. For instance, mobile based cab services like Uber and Ola have disrupted the cab hire market, met technology will soon be disrupting established agency market, and marketplaces could disrupt agencies as well as search platforms. Wallets have disrupted traditional methods of payments and Adhaar or UPI could perhaps disrupt wallets in the near future, hence there cannot be a better time for path breaking disruption and the Indian travel industry is well poised to do so. We feel that the onus on disrupting existing technology ecosystem is on the existing players. The companies in travel industry must be able to spot the emerging trends and be able to pivot the organization to become future-ready.

While positive strides are being made in each of these aspects, India still considerably lags in comparison to most nations globally. Several major players in the Indian travel and hospitality sector cite payments as one of the key pressing concerns. The issues concerning payments include lack of integration between the payment systems of banks, mobile wallets and merchants, high cost of digital transactions and lack of facilitation of foreign currency payments. The travel and hospitality sector deals with a large amount of data comprising personal information of travellers, financial transactions and customer behaviour. With increasing digitisation in travel - especially the growth of mobile wallets, Unified Payments Interface (UPI), internet banking and other such digital initiatives taken by the government - the risks of data security are bound to rise

\section{REFERENCES:}

1. "Digitalisation of India's travel and hospitality sector”, Sudipto Roy March 7, 2017,Digital News, Kolkata

2. "Indian tourism ministry goes digital", Surbhi Kapila September 5, 2017,B2B Travel News, New Delhi

3. "Travel and tourism: Automation will be the industry's poster boy”, Priyanka Ganwani, Feb 06th 2017

4. "technology takes over, changing the landscape of travel \& tourism in India”, Anurag Tiwari

5. https://assets.kpmg.com/content/dam/kpmg/.../FIC CI-travel-hospitality -gone-digital.pdf 